\title{
PROGNOSTIC FACTORS FOR CLINICAL OUTCOMES AFTER ROTATOR CUFF REPAIR
}

\author{
José Otávio Reggi Pécora ${ }^{1}$, Eduardo Angeli Malavolta ${ }^{1}$, Jorge Henrique Assunção ${ }^{1}$, Mauro Emílio Conforto Gracitelli ${ }^{1}$, \\ João Paulo Sobreiro Martins ${ }^{1}$, arnaldo Amado Ferreira Neto ${ }^{1}$
}

\section{ABSTRACT}

Objective: To identify prognostic factors of postoperative functional outcomes. Methods: Retrospective case series evaluating patients undergoing rotator cuff repair, analyzed by the UCLA score (pre and 12-month postoperative) and Magnetic Resonance Imaging (preoperative). Patients' intrinsic variables related to the injury and intervention were evaluated. Multivariate linear regression analysis was performed to determine variables impact on postoperative functional assessment. Results: 131 patients were included. The mean UCLA score increased from $13.17 \pm 3.77$ to $28.73 \pm 6.09(p<0,001)$. We obtained $65.7 \%$ of good and excellent results. Age $(r=0.232, p=0.004)$ and reparability of posterosuperior injuries $(r=0.151, p=0.043)$ correlated with the functional assessment at 12 months. After multivariate linear regression analysis, only age was associated $(p=0.008)$. Conclusions: The surgical treatment of rotator cuff tears lead to good and excellent results in $65.6 \%$ of patients. Age was an independent predictor factor with better clinical outcomes by UCLA score in older patients. Level of Evidence IV, Case Series.

Keywords: Rotator cuff. Arthroscopy. Prognosis. Evaluation of results of therapeutic interventions.

Citation: Pécora JOR, Malavolta EA, Assunção JH, Gracitelli MEC, Martins JPS, Ferreira Neto AA. Prognostic factors for clinical outcomes after rotator cuff repair. Acta Ortop Bras. [online]. 2015;23(3):146-9. Available from URL: http://www.scielo.br/aob.

\section{INTRODUCTION}

The tendinopathies of the rotator cuff are the leading cause of shoulder pain ${ }^{1}$ and tears of these tendons affect $20.7 \%$ of the population. ${ }^{2}$ The increasing number of surgical repair of these injuries ${ }^{3}$ generates high costs to the health systems. ${ }^{4}$ The arthroscopic repair of the rotator cuff leads to satisfactory clinical outcomes in up to $93 \%$ of pacients. ${ }^{5,6}$ However, the rate of tear recurrence ranges from 4 to $94 \%{ }^{7,8}$

Several intrinsic factors of the patient, injury or surgery have been associated with the outcomes of treatment of the rotator cuff injuries. ${ }^{9-14}$ Determining prognostic factors helps identifying patients at increased risk of unsatisfactory development, and elaborate strategies that reduce this occurrence.

Several studies ${ }^{11-13,15}$ seek correlations isolated and fragmentedly. ${ }^{16}$ Few studies performed independently, through a multivariate analysis, search for predictors of rotator cuff surgical treatment outcomes. ${ }^{9,17}$ It is known that this form of analysis reduces the confounding factors in the evaluation of different prognostic criteria. ${ }^{18}$

The primary objective of this study was to identify which prognostic factors independently correlate with clinical outcome of patients undergoing repair of the rotator cuff. As a secondary objective we evaluated the clinical outcomes of the procedure.

\section{METHODS}

A retrospective case series was performed, evaluating patients undergoing rotator cuff repair arthroscopically. The procedures were performed by five different surgeons, which are part of the Shoulder and Elbow Group at our institution. The surgeries took place between June 2006 and April 2013. This study was approved by the Ethics Committee of our institution under the number 696.

Our analysis did not include patients with glenohumeral instability, glenohumeral osteoarthritis, adhesive capsulitis, inflammatory arthropathy or those who did not have preoperative functional assessment and at 12 months follow-up.

In the preoperative period, patients were clinically evaluated by the method of the University of California at Los Angeles (UCLA) and magnetic resonance imaging (MRI). In the postoperative evaluation, the UCLA scale was applied at 12 months of followup, as well as Ellmann's categorized assessment. ${ }^{19}$

The following variables were recorded:

All the authors declare that there is no potential conflict of interest referring to this article.

1. Institute of Orthopedics and Traumatology, Hospital das Clínicas da Faculdade de Medicina da Universidade de São Paulo, São Paulo, SP, Brazil.

Work developed at the Institute of Orthopedics and Traumatology, Hospital das Clínicas da Faculdade de Medicina da Universidade de São Paulo, São Paulo, SP, Brazil. Correspondence: Jorge Henrique Assunção, Rua Dr. Ovídio Pires de Campos, 333, Cerqueira Cesar 05403-010 São Paulo, SP, Brazil. jhassuncao@uol.com.br 
1) Intrinsic to the patient: gender, age and affected side.

2) Related to the injury: type of acromion, ${ }^{20}$ affected tendon, injury type (partial or full thickness), and DeOrio and Cofield ${ }^{21}$ rating for posterior superior tears and Lafosse et al. ${ }^{22}$ classification for the subscapularis tears;

3) Related to the intervention: procedure carried out in posterior superior portion of the rotator cuff (supraspinatus and/ or infraspinatus) and subscapularis (none, debridement, partial or total repair), on the long head of the biceps (none, tenotomy or tenodesis), on the distal portion of the clavicle (none, resection of the inferior osteophytes or Mumford procedure) and acromioplasty.

The procedures were performed under general anesthesia associated with interscalene block. Antimicrobial prophylaxis with first-generation cephalosporin for 24 hours was used. Patients were placed in beach chair and conventional portals (posterior, anterior and lateral) were used. When necessary, additional portals were performed.

Bursectomy was performed in all cases. Acromioplasty was performed in cases where there was tear involving the supraspinatus, provided that it was completely repairable and was not part of an massive rupture. The procedure in the biceps tendon was done in cases with partial tears or instability. Tenotomy was chosen in patients over 60 years old and tenodesis in younger patients. Resection of the distal clavicle portion was indicated when there was pain symptoms associated with acromioclavicular joint disease. The suture of the rotator cuff was performed after debridement of the greater tuberosity, using simple row of anchors and ungrounded points.

Postoperatively, patients were maintained on a sling for six weeks. Active movements to the elbow, wrist and fingers were started on the first day. Passive motion to the shoulder was initiated after three weeks, allowing up to $90^{\circ}$ flexion, external rotation and abduction as tolerable. After six weeks, assisted active and free movements in all planes were performed. Strengthening was started after three months.

\section{Statistical analysis}

Continuous variables were evaluated for their normality using the Kolmogorov-Smirnov test and homogeneity, through the Levene test.

The non-parametric Wilcoxon test was used to analyze the impact of surgical treatment on the functional UCLA scale, comparing the preoperative scores to those at 12 months postoperatively. The Pearson correlation coefficients were calculated to determine the correlation between postoperative scores and intrinsic variables to the patient, the injury and the intervention. For continuous or ordinal variables, a positive correlation indicates that as the value of the variable increases, the post-operative score is also higher. A negative correlation indicates the opposite. For dichotomous variables, a positive correlation indicates that when the variable is present, the postoperative score is higher. A negative correlation indicates the opposite. Regarding gender, a positive correlation indicates that females have higher postoperative score. A negative correlation indicates better results in males, instead.

We performed a multivariate linear regression in order to define the independent variables influencing clinical outcomes at the end of follow-up.

For data analysis we used the SPSS software version 20.0, adopting a significance level of $5 \%$.

\section{RESULTS}

In the study period, 491 patients with pathologies of the rotator cuff were operated at our institution. After selection by the inclusion and non-inclusion criteria, our study included 131 patients (131 shoulders). Of these, $80(61.1 \%)$ were female and 99 (75.6\%) had the right side operated. The mean age was $54.97 \pm 8.79$ years old

Variables related to the injury, defined by the preoperative imaging studies, are shown in Table 1. The variables related to intervention were detailed in Table 2.

According to the UCLA classification, the average score was $13.17 \pm 3.77$ in the preoperative evaluation and $28.73 \pm 6.09$ at 12 months of follow-up, showing significant improvement $(p<0.001)$. We obtained 47 (35.9\%) patients with excellent results, 39 (29.8\%) with good results, and 45 (34.3\%) had unsatisfactory outcomes, according to Ellman's classification.

The correlations between the variables intrinsic to the patient, related to the injury and to the intervention are shown in Table 3. The only variables that correlated with the functional outcome at 12 months postoperative were age $(r=0.232, p=0.004)$ and performed procedure in the posterior superior rupture $(r=0.151, p=0.043)$.

According to multivariate linear regression, from all variables, only age was independently correlated with the functional evaluation at 12 months $(p=0.008)$. From the data obtained, we can expect a higher score in 0.161 points (range $0.043-0.242,95 \% \mathrm{Cl}$ ) by the UCLA scale to each additional patient's year of age.

\begin{tabular}{|c|c|c|}
\hline Variables analyzed & $\mathrm{n}$ & $\%$ \\
\hline \multicolumn{3}{|l|}{ Acromion type } \\
\hline Flat & 10 & 7.6 \\
\hline Curved & 93 & 71.0 \\
\hline hooked & 28 & 21.4 \\
\hline \multicolumn{3}{|l|}{ Tear of the supraspinatus tendon } \\
\hline Partial & 7 & 5.3 \\
\hline Small & 25 & 19.1 \\
\hline Medium & 73 & 55.7 \\
\hline Large & 22 & 16.8 \\
\hline massive & 4 & 3.1 \\
\hline \multicolumn{3}{|l|}{ Tear of the subscapularis tendon } \\
\hline Absent or partial articular & 77 & 58.8 \\
\hline Complete lesion of superior $1 / 3$ & 48 & 36.6 \\
\hline Complete lesion of superior $2 / 3$ or the whole extension & 6 & 4.6 \\
\hline
\end{tabular}


Table 2. Variables related to the intervention

\begin{tabular}{|c|c|c|}
\hline Variables analyzed & $\mathbf{n}$ & $\%$ \\
\hline \multicolumn{3}{|c|}{ Posterior superior repair } \\
\hline Not performed & 4 & 3.1 \\
\hline debridement & 8 & 6.1 \\
\hline Partial repair & 6 & 4.6 \\
\hline Complete repair & 113 & 86.3 \\
\hline \multicolumn{3}{|l|}{ Subscapular repair } \\
\hline Not performed & 79 & 60.3 \\
\hline debridement & 34 & 26.0 \\
\hline Partial repair & 4 & 3.1 \\
\hline Complete repair & 14 & 10.7 \\
\hline \multicolumn{3}{|l|}{ Procedure on biceps } \\
\hline None & 79 & 60.3 \\
\hline Tenotomy & 13 & 9.9 \\
\hline Tenodesis & 39 & 29.8 \\
\hline \multicolumn{3}{|c|}{ Lateral resection of the clavicle } \\
\hline Yes & 30 & 22.9 \\
\hline No & 101 & 77.1 \\
\hline \multicolumn{3}{|l|}{ Acromioplasty } \\
\hline Yes & 118 & 90.1 \\
\hline No & 13 & 9.9 \\
\hline
\end{tabular}

Table 3. Univariate correlations between the variables analyzed and the functional outcome by the UCLA scale at 12 months.

\begin{tabular}{c|c|c}
\hline Variable & Absolute correlation (r) & $p$ \\
\hline Gender & -0.041 & 0.32 \\
\hline Age $^{1}$ & 0.232 & $0.004^{*}$ \\
\hline Acromion type $^{1}$ & -0.095 & 0.141 \\
\hline Length of the posterior superior tear $^{1}$ & 0.07 & 0.212 \\
\hline Length of the subscapular tear $^{1}$ & -0.005 & 0.476 \\
\hline Procedure on the posterior superior tear $^{1}$ & 0.151 & $0.043^{*}$ \\
\hline Procedure on the subscapular $^{1}$ & -0.01 & 0.453 \\
\hline Procedure on the biceps $^{2}$ & -0.08 & 0.183 \\
\hline Lateral resection of the clavicle $^{2}$ & -0.005 & 0.476 \\
\hline Acromioplasty & & 0.016 \\
\hline
\end{tabular}

1: Continuous or ordinal variables; 2 : Dichotomous variables.

\section{DISCUSSION}

Our series included 131 patients, a significant number for the national literature. Checchia et al. ${ }^{5}$ and Godinho et al. ${ }^{6}$ described the results of 141 and 100 patients, respectively. Like other authors, our results showed significant improvement with the procedure. According to Ellmann's classification, we obtained $65.7 \%$ of excellent or good results, values similar to those of Godinho et al. ${ }^{6}(67 \%)$, but lower than those of Checchia et al. ${ }^{5}(93.7 \%)$. It is worth noting that we performed clinical assessments in a standardized way at 12 months, unlike others (average follow-up over 24 months in both cases). With longer follow-up one could expect an increased score. ${ }^{23}$

McElvany et al. ${ }^{16}$ performed a meta-analysis evaluating the functional outcomes of the rotator cuff repair. In 90 studies, the score obtained in the postoperative period was on average $103 \%$ (range $21-272 \%$ ) higher than preoperatively, results close to the $118 \%$ improvement obtained by us. The authors also observed by evaluating 102 studies that the average score after surgery is $85 \%$ (range $64-97 \%$ ) of the maximum allowed by the scales. In our study, the average score represented $82 \%$ of the maximum allowed by the UCLA scale.

This study demonstrated that only the patient's age correlated independently with clinical outcomes in multivariate regression, in a positive way. This is in contrary to some authors, ${ }^{9,24}$ describing worst rating by the functional scales in older patients. However, other autores ${ }^{13,25}$ observe worse clinical outcomes and lower satisfaction in younger patients. Possible explanations for best results with increasing age may be less functional demand and lower incidence of labor issues. In addition, the UCLA scale, used as a measure of outcome, does not evaluate strength accurately, but categorized. ${ }^{26}$ Thus, the results may not apply to analyzes by other scales and this may be an explanation for the best results having occurred in the older population.

We also observed that the univariate correlation showed that the posterior superior rupture repair procedure also influenced the clinical outcome, with better results in cases with complete repair of the injury. Similarly, O'Holleran et al. ${ }^{27}$ showed that patients with not repairable extensive ruptures and sudmitted only to surgical debridement had worse functional outcomes. Some authors showed correlation of the dimension of the rupture with clinical outcomes, with larger injuries leading to lesser satisfaction, ${ }^{27}$ more tear recurrences ${ }^{17}$ and worst functional outcomes. ${ }^{9,11,12}$ Our data did not show similar findings. However, the small number of patients with extensive ruptures limits our conclusions regarding this variable.

There is no consensus regarding the influence of gender in the final outcome. Better clinical outcomes both in men ${ }^{9,11,12,16}$ as in women ${ }^{13}$ are described. In our study, as in Gulotta's et al. ${ }^{17}$ and Vastamäki's et al., ${ }^{10}$ there was no effect of this variable in the postoperative clinical outcomes .

The performance of tenotomy or tenodesis of the long head of the biceps, and the resection of the distal end of the clavicle also did not affect clinical outcomes. These results are in agreement with other authors ${ }^{9,11,12}$ and indicate that these procedures associated to rotator cuff repair have little influence on functional outcome. We had in our sample a small number of patients not undergoing acromioplasty, which limits our findings on this not being a predictor. Nevertheless, current evidence indicates that holding the anterior inferior resection of the acromion does not change the clinical outcomes. ${ }^{28}$

It was not possible to assess other variables that could influence the results, as the degree of fatty degeneration of the muscles, ${ }^{10,14}$ the activity level of patients, ${ }^{10}$ symptomatology span, ${ }^{10}$ and labor issues, ${ }^{13}$ the latter being a limitation of our study. The absence of postoperative imaging studies in our analysis is also open to criticism. It is worth noting that failure to detect correlations among the other variables may be due to a Type II error, determined by an insufficient sample.

As a favorable point of our study we can mention the large series 
according to national standards, our knowledge being of only one article evaluating a higher number of patients with rotator cuff disorders. ${ }^{5}$ Moreover, conducting a multivariate analysis allows the control and evaluation of different prognostic criteria, reducing confounding factors when compared to an univariate analysis. ${ }^{18}$ Our results come contribute for the understanding of the prognostic factors of treatment of these injuries, a field with still no consensus in the orthopedic literature. We believe that further studies are needed, including larger databases and eventually multicenter collaboration, to provide more concrete answers.

\section{CONCLUSION}

The surgical treatment of rotator cuff tears led to good and excellent results in $65.6 \%$ of patients. Age was an independent predictor, with better clinical outcomes by the UCLA scale in elderly patients.

\section{REFERENCES}

1. Mitchell C, Adebajo A, Hay E, Carr A. Shoulder pain: diagnosis and management in primary care. BMJ. 2005;331(7525):1124-8.

2. Yamamoto A, Takagishi K, Osawa T, Yanagawa T, Nakajima D, Shitara H, et al. Prevalence and risk factors of a rotator cuff tear in the general population. J Shoulder Elbow Surg. 2010;19(1):116-20.

3. Colvin AC, Egorova N, Harrison AK, Moskowitz A, Flatow EL. National trends in rotator cuff repair. J Bone Joint Surg Am. 2012;94(3):227-33.

4. Churchill RS, Ghorai JK. Total cost and operating room time comparison of rotator cuff repair techniques at low, intermediate, and high volume centers: mini-open versus all-arthroscopic. J Shoulder Elbow Surg. 2010;19(5):716-21.

5. Checchia SL, Doneux PS, Miyazaki AN, Fregoneze M, Silva LA, Ishi M, et al. Avaliação dos resultados obtidos na reparação artroscópica das lesões do manguito rotador. Rev Bras Ortop. 2005;40(5):229-38.

6. Godinho GG, França FO, Freitas JMA, Watanabe FN, Nobre LO, De Almeida Neto MA, et al. Avaliação da integridade anatômica por exame de ultrassom e funcional pelo índice de Constant \& Murley do manguito rotador após reparo artroscópico. Rev Bras Ortop. 2010;45(2):174-80.

7. Galatz LM, Ball CM, Teefey SA, Middleton WD, Yamaguchi K. The outcome and repair integrity of completely arthroscopically repaired large and massive rotator cuff tears. J Bone Joint Surg Am. 2004;86(2):219-24

8. Malavolta EA, Gracitelli ME, Ferreira Neto AA, Assunção JH, Bordalo-Rodrigues $\mathrm{M}$, de Camargo OP. Platelet-rich plasma in rotator cuff repair: a prospective randomized study. Am J Sports Med. 2014;42(10):2446-54.

9. Oh JH, Kim SH, Ji HM, Jo KH, Bin SW, Gong HS. Prognostic factors affecting anatomic outcome of rotator cuff repair and correlation with functional outcome. Arthroscopy. 2009;25(1):30-9.

10. Vastamäki M. Factors influencing the operative results of rotator cuff rupture. Int Orthop. 1986;10(3):177-81.

11. Nho SJ, Shindle MK, Adler RS, Warren RF, Altchek DW, MacGillivray JD. Prospective analysis of arthroscopic rotator cuff repair: subgroup analysis. $J$ Shoulder Elbow Surg. 2009;18(5):697-704.

12. Cofield RH, Parvizi J, Hoffmeyer PJ, Lanzer WL, Ilstrup DM, Rowland CM.Surgical repair of chronic rotator cuff tears. A prospective long-term study. J Bone Joint Surg Am. 2001;83(1):71-7.

13. Watson EM, Sonnabend DH. Outcome of rotator cuff repair. J Shoulder Elbow Surg. 2002;11(3):201-11.

14. Gladstone JN, Bishop JY, Lo IK, Flatow EL. Fatty infiltration and atrophy of the rotator cuff do not improve after rotator cuff repair and correlate with poor functional outcome. Am J Sports Med. 2007;35(5):719-28.
15. Tashjian RZ, Bradley MP, Tocci S, Rey J, Henn RF, Green A. Factors influencing patient satisfaction after rotator cuff repair. J Shoulder Elbow Surg. 2007;16(6):752-8.

16. McElvany MD, McGoldrick E, Gee AO, Neradilek MB, Matsen FA 3rd. Rotator cuff repair: published evidence on factors associated with repair integrity and clinical outcome. Am J Sports Med. 2015;43(2):491-500.

17. Gulotta LV, Nho SJ, Dodson CC, Adler RS, Altchek DW, MacGillivray JD; HSS, Arthroscopic Rotator Cuff Registry. Prospective evaluation of arthroscopic rotator cuff repairs at 5 years: part II--prognostic factors for clinical and radiographic outcomes. J Shoulder Elbow Surg. 2011;20(6):941-6.

18. Südkamp NP, Audigé L, Lambert S, Hertel R, Konrad G. Path analysis of factors for functional outcome at one year in 463 proximal humeral fractures. J Shoulder Elbow Surg. 2011;20(8):1207-16.

19. Ellman H, Hanker G, Bayer M. Repair of the rotator cuff. End-result study of factors influencing reconstruction. J Bone Joint Surg Am. 1986;68(8):1136-44.

20. Bigliani L, Morrison D, April E. The morphology of the acromion and its relationship to rotator cuff tears. Orthop Trans. 1986;10:228.

21. DeOrio JK, Cofield RH. Results of a second attempt at surgical repair of a failed initial rotator-cuff repair. J Bone Joint Surg Am. 1984;66(4):563-7.

22. Lafosse L, Jost B, Reiland Y, Audebert S, Toussaint B, Gobezie R. Structural integrity and clinical outcomes after arthroscopic repair of isolated subscapularis tears. J Bone Joint Surg Am. 2007;89(6):1184-93.

23. Pennington WT, Gibbons DJ, Bartz BA, Dodd M, Daun J, Klinger J, et al. Comparative analysis of single-row versus double-row repair of rotator cuff tears. Arthroscopy. 2010;26(11):1419-26.

24. Romeo AA, Hang DW, Bach BR Jr, Shott S. Repair of full thickness rotator cuff tears. Gender, age, and other factors affecting outcome. Clin Orthop Relat Res.1999;(367):243-55

25. Sperling JW, Cofield RH, Schleck C. Rotator cuff repair in patients fifty years of age and younger. J Bone Joint Surg Am. 2004;86(10):2212-5.

26. Burkhart SS, Cole BJ. Bridging self-reinforcing double-row rotator cuff repair: we really are doing better. Arthroscopy. 2010;26(5):677-80.

27. O'Holleran JD, Kocher MS, Horan MP, Briggs KK, Hawkins RJ. Determinants of patient satisfaction with outcome after rotator cuff surgery. J Bone Joint Surg Am. 2005;87(1):121-6.

28. Chahal J, Mall N, MacDonald PB, Van Thiel G, Cole BJ, Romeo AA, et al. The role of subacromial decompression in patients undergoing arthroscopic repair of full-thickness tears of the rotator cuff: a systematic review and meta-analysis. Arthroscopy. 2012;28(5):720-7. 